\title{
Clinicopathologic features of invasive metaplastic and micropapillary breast carcinoma: comparison with invasive ductal carcinoma of breast
}

\author{
Atif Ali Hashmi', Saher Aijaz², Raeesa Mahboob', Saadia Mehmood Khan', Muhammad Irfan³, Narisa Iftikhar', \\ Mariam Nisar ${ }^{1}$, Maham Siddiqui ${ }^{4}$, Muhammad Muzzammil Edhi ${ }^{6}$, Naveen Faridi ${ }^{5}$ and Amir Khan ${ }^{7^{*}}$ (1)
}

\begin{abstract}
Objectives: The aim of this study was to determine the frequency of metaplastic breast carcinoma and invasive micropapillary carcinoma in our population and also to compare the clinico-pathologic features of metaplastic breast carcinoma and invasive micropapillary carcinoma with invasive ductal carcinoma, not otherwise specified (IDC, NOS).

Results: $86.9 \%$ of the cases were identified as ductal carcinoma, NOS, while $2.2 \%$ were metaplastic and $0.76 \%$ cases were micropapillary carcinoma. Metaplastic carcinomas were found to be of higher grade as compared to IDC, NOS as $81 \%$ of metaplastic carcinoma were grade III compared to $35 \%$ IDC, NOS. $79 \%$ of metaplastic carcinoma were ER negative and $86 \%$ were PR negative, respectively as compared to ductal carcinoma NOS, which were $40 \%$ ER negative and 54\% were PR. Similarly, 86.7\% micropapillary cancers were ER positive and $73.3 \%$ were PR positive. Moreover, $66.7 \%$ micropapillary carcinoma showed nodal metastasis and $77.8 \%$ showed lymphovascular invasion, which was significantly higher than that of IDC, NOS micropapillary and metaplastic carcinomas accounts for less than 2 and 1\% of the breast cancer burden in our population and highly correlates with poor prognosis parameters therefore, require more intensive management in our population.
\end{abstract}

Keywords: Metaplastic carcinoma, Micropapillary carcinoma, ER, PR, Her2neu, Breast cancer

\section{Introduction}

Due to heterogeneous nature of the breast cancer, understanding of potentially aggressive cancers helps in designing tailored therapeutic interventions as it assists in comprehending the prognosis of the disease. Metaplastic breast carcinomas (MBC) and invasive micropapillary breast carcinomas (IMBC) are two aggressive phenotypic variants of breast cancers with a low prevalence rate amongst the general population. Although these variants are relatively rare but pose significant challenge in terms of breast cancer treatment. Majority of the special subtypes of breast carcinoma including mucinous, tubular,

\footnotetext{
*Correspondence: dramirkhan04@gmail.com

${ }^{7}$ Department of Medicine, Kandahar University, Kandahar, Afghanistan

Full list of author information is available at the end of the article
}

cribriform etc. are more indolent in behavior than conventional ductal carcinoma, not otherwise specified, and confers relatively better prognosis and favorable outcomes [1-3]. Invasive micropapillary carcinoma is recognized by tubulo-alveolar formation, which is visible in empty spaces with fragile pseudopapillary structures devoid of fibro-vascular core scattered across the membrane [4]. This micropapillary differentiation is visible as tight clusters of tumor cells present in cleft like retraction spaces resembling lymphatics [5]. Clinical significance of micropapillary differentiation relies on high incidence of nodal metastasis [6]. Metaplastic carcinomas are a diverse group of tumors showing divergent differentiation towards squamous, spindle cell or mesenchymal. These tumors are found to be negative for hormone receptors and Her2neu and therefore exhibit a basal like 
breast cancer profile $[7,8]$. As a consequence of systemic metastasis, they are regarded as one of the most aggressive breast tumors [9]. Epithelial to mesenchymal transition in these subtypes of breast carcinomas are proposed to be associated with the tendency of the tumor cells to acquire properties of stem cells [10]. Since these subtypes of breast cancers are less responsive to conventional hormonal and chemotherapeutic interventions, we aimed to evaluate the frequency of metaplastic breast carcinoma and invasive micropapillary carcinoma in our population with regard to clinico-pathologic features of invasive ductal carcinoma, not otherwise specified. Moreover, in the era of personalized therapy, knowledge of histologic and prognostic parameters of individual types of cancers is extremely important as these features may differ in different populations. Therefore, evaluating prognostic features of micropapillary and metaplastic breast cancer in this study will be helpful in individualizing treatment strategies in locoregional population.

\section{Main text Methods}

We reviewed 1951 cases of breast carcinoma treated at Liaquat National hospital from January 2008 till December 2014. The specimens include trucut biopsies, breast conservation surgeries and modified radical mastectomies. All the slides of these cases were retrieved and reviewed by two experienced pathologists. Micropapillary differentiation was defined as tumor nests present in cleft like spaces resembling lymphatic spaces. Micropapillary carcinomas were defined as tumors with $>90 \%$ micropapillary differentiation (Fig. 1). Metaplastic carcinomas were categorized as tumors showing spindle cell, squamous or mesenchymal differentiation (osseous, chondroid or matrix producing stroma) as shown in Fig. 1. Histopathologic characteristics recorded include tumor type, size, grade and lymph node status along with degree of necrosis, lymphocytic reaction and fibrosis. One representative
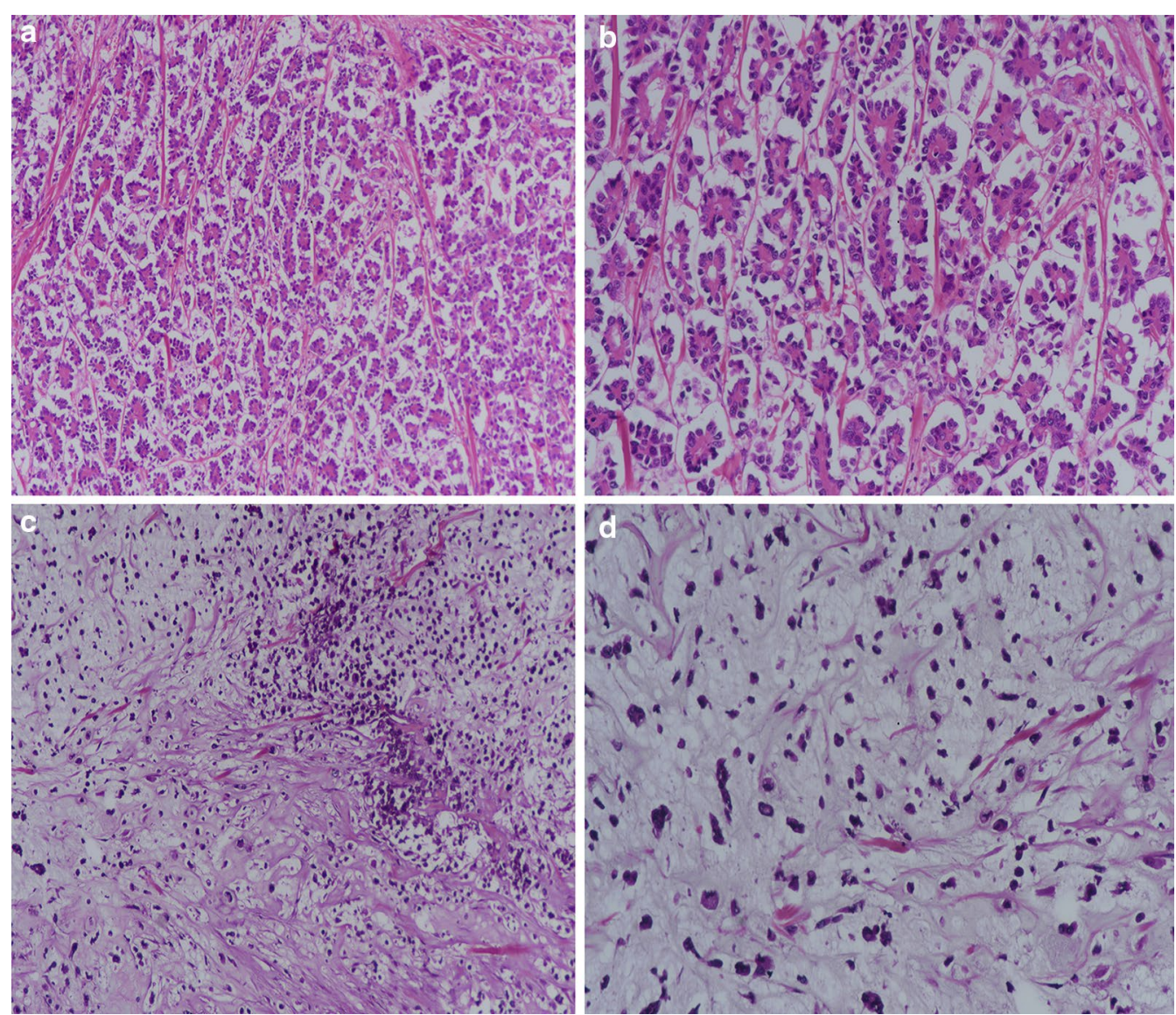

Fig. 1 a Microscopic sections of Micropapillary carcinoma, $\times 40$ showing tumor cells in cleft like retraction spaces. b Microscopic sections of Micropapillary carcinoma, $\times 200$ showing reverse polarization of tumor cells. c Microscopic sections of Metaplastic carcinoma showing spindled tumor cells with myxoid matrix producing stroma, $\times 40$ magnification. $\mathbf{d}$ Microscopic sections of Metaplastic carcinoma, $\times 200$ magnification, showing tumor cells floating in chondromyxoid stroma 
section is selected for IHC studies including ER, PR, her2neu and ki67 by DAKO envision method. Following antibodies are used.

1. FLEX Monoclonal Rabbit Anti-human Estrogen receptor alpha, clone EP1, ready to use, purchased from DAKO (code IR084).

2. FLEX Monoclonal Mouse Anti-human Progesterone receptor, clone PgR 636, ready to use, purchased from DAKO (code IR068).

3. Polyclonal Rabbit Anti-human c-erbB-2 oncoprotein, purchased from DAKO (code A0485).

4. FLEX Monoclonal Mouse Anti-human, Ki67 Antigen, Clone MIB-1, Ready to use, purchased from DAKO (code IR626).

Immunohistochemistry was performed using DAKO envision kit according to manufacturers recommendations. Normal breast tissue was used as positive controls for ER, PR and as negative control for Her2neu. Known case of her2neu amplified breast cancer was used as positive control for Her2neu. For ki67 benign reactive lymph node was used as positive control.

More than 1\% nuclear staining for ER/PR was considered positive expression.

HER2neu were scored based on the intensity and percentage of positive cells on a scale of 0 to $3+$ according to ASCO/CAP guidelines [11, 12]. Cases with intermediate $(2+)$ expression of Her2neu underwent subsequent FISH testing for Her2neu gene amplification. FISH testing was performed using FDA approved Path Vysion Her2 DNA Probe kit according and reported according to CAP guidelines.

$\mathrm{Ki}-67$ immunoreactivity was recorded as continuous variables, based on the proportion of positive tumor cells $(0-100 \%)$. At least 1000 cells were evaluated before calculating an average estimate. If hot spots were present, then they are included in the estimation. Ki67 index was further categorized into four groups, $<14 \%, 15-24 \%$, $25-44 \%,>45 \%$.

Statistical package for social sciences (SPSS 21) was used for data compilation and analysis. Mean and standard deviation were calculated for quantitative variables. Frequency and percentage were calculated of qualitative variables. Chi square was applied to see association. $T$ test was applied to compare difference in means among groups by considering P-value $\leq 0.05$ as significant.

\section{Results}

The study involved 1951 cases of primary breast carcinoma, out of which 1695 (86.9\%) cases were ductal carcinoma, NOS, while $43(2.2 \%)$ and $15(0.76 \%)$ cases were of metaplastic and micropapillary carcinoma, respectively and thus included in the study. Table 1 shows the comparison of metaplastic carcinoma with ductal carcinoma, NOS.

Metaplastic carcinomas were found to be of higher grade as compared to ductal carcinoma NOS $(81 \%$ of metaplastic carcinoma were grade III compared to $35 \%$ ductal carcinoma, NOS). Similarly, metaplastic carcinoma differs with ductal carcinoma NOS in terms of ER/ PR positivity. 79 and $86 \%$ of metaplastic carcinoma were ER and PR negative, respectively as compared to ductal carcinoma NOS (40 and 54\% were ER and PR negative, respectively). No significant difference was noted in respect to $\mathrm{T}$-stage and $\mathrm{N}$-stage of metaplastic carcinoma as compared to ductal carcinoma NOS. Lack of insitu component was noted in more than half of cases of metaplastic carcinoma which differs significantly from ductal carcinoma NOS. Majority of metaplastic carcinomas were triple negative (67.4\%) compared to ductal carcinoma NOS, most of which are luminal B (44\%).

Table 2 shows the comparison of various clinico-pathologic features of micropapillary carcinoma with ductal carcinoma NOS. No significant association was noted except for ER and PR positivity, where micropapillary cancers were noted to have more frequent positivity of these biomarkers (micropapillary cancers were 86.7 and 73.3\% ER and PR positive compared to 60 and $46 \%$ in ductal carcinoma NOS).

Although micropapillary cancers were found to be associated with $66.7 \%$ frequency of nodal metastasis, however to significant difference was noted when compared to ductal carcinoma NOS. Furthermore, mean ki67 index of micropapillary carcinoma was 35.8 and $26 \%$ were of grade III. Her2neu positivity was noted in $60 \%$ of cases. Higher frequency of lymphovascular invasion was noted in micropapillary carcinoma (77.8\%) compared to ductal carcinoma NOS (24.8\%). $86.7 \%$ of micropapillary carcinoma were luminal B compared to $44 \%$ of ductal carcinoma, NOS.

\section{Discussion}

In the present study we found a low frequency of metaplastic and micropapillary carcinoma, however these rare types were found to be associated with adverse prognostic parameters. Metaplastic carcinomas were noted to have higher grade and lower expression of hormonal receptors, while micropapillary carcinoma showed higher frequency of lymphovascular invasion. Clinico-pathologic evaluation of tumors is principal to predict the outcome and life expectancy of the patients. On account of the recognition of ductal carcinomas and previously classified as not otherwise specified carcinomas, today the rate of treatment failure has been largely reduced [13]. An antecedent study conducted in the 
Table 1 Association of clinico-pathologic parameters of metaplastic breast cancer subtype with Ductal carcinoma, NOS

\begin{tabular}{|c|c|c|c|c|}
\hline & \multicolumn{3}{|l|}{ n (\%) } & \multirow[t]{2}{*}{ P-value } \\
\hline & Metaplastic & Ductal, NOS & Total & \\
\hline Age (years) ${ }^{\mathrm{ab}}$ & $49.21 \pm 12.92$ & $50.54 \pm 12.48$ & - & 0.49 \\
\hline \multicolumn{5}{|c|}{ Age group $(n=1738)$} \\
\hline$\leq 30$ & $3(3.3)$ & $89(5.3)$ & $92(5.3)$ & \multirow[t]{4}{*}{0.767} \\
\hline $31-50$ & $21(48.8)$ & $822(48.8)$ & $843(48.5)$ & \\
\hline $51-70$ & $16(37.2)$ & $692(40.8)$ & $708(40.7)$ & \\
\hline$>70$ & $3(7)$ & $92(5.4)$ & $95(5.5)$ & \\
\hline \multicolumn{5}{|c|}{ Tumor grade $(n=1738)$} \\
\hline Grade 1 & $3(7)$ & $160(9.4)$ & $163(9.4)$ & \multirow[t]{3}{*}{$\leq 0.05$} \\
\hline Grade 2 & $5(11.6)$ & $945(55.8)$ & $950(54.7)$ & \\
\hline Grade 3 & $35(81.4)$ & $590(34.8)$ & $625(36)$ & \\
\hline Ki67 value ${ }^{\mathrm{ab}}$ & $40.05 \pm 22.67$ & $35.92 \pm 23.33$ & - & 0.252 \\
\hline \multicolumn{5}{|c|}{ Ki67 index category $(n=1738)$} \\
\hline$<15$ & $4(9.3)$ & $373(22)$ & $377(21.7)$ & \multirow[t]{4}{*}{0.203} \\
\hline $15-24$ & $11(25.6)$ & $311(18.3)$ & $322(18.5)$ & \\
\hline $25-44$ & $12(27.9)$ & $406(24)$ & $418(24.1)$ & \\
\hline$>44$ & $16(37.2)$ & $605(35.7)$ & $621(35.7)$ & \\
\hline Size of tumor ${ }^{\mathrm{ab}}$ & $36.77 \pm 15.31$ & $36.11 \pm 14.84$ & - & 0.825 \\
\hline \multicolumn{5}{|c|}{ Tumor stage $(n=660)$} \\
\hline $\mathrm{T} 1$ & $4(15.4)$ & $83(13.1)$ & $87(13.2)$ & \multirow[t]{3}{*}{0.695} \\
\hline $\mathrm{T} 2$ & $17(65.4)$ & 454 (71.6) & $471(71.4)$ & \\
\hline T3 & $5(19.2)$ & $97(15.3)$ & $102(15.5)$ & \\
\hline \multicolumn{5}{|c|}{ Nodal status $(n=660)$} \\
\hline Positive & $12(46.2)$ & $318(50.2)$ & $330(50)$ & \multirow[t]{2}{*}{0.689} \\
\hline Negative & $14(53.8)$ & $316(48.8)$ & $330(50)$ & \\
\hline \multicolumn{5}{|l|}{$N$ stage $(n=660)$} \\
\hline NO & $14(53.8)$ & $320(50.5)$ & $334(50.6)$ & \multirow[t]{4}{*}{0.431} \\
\hline $\mathrm{N} 1$ & $5(19.2)$ & $130(20.5)$ & $135(20.5)$ & \\
\hline N2 & $1(3.8)$ & $85(13.4)$ & $86(13)$ & \\
\hline N3 & $6(23.1)$ & 99 (15.6) & $105(15.9)$ & \\
\hline \multicolumn{5}{|c|}{ Laterality $(\mathrm{n}=1738)$} \\
\hline Left & $19(44.2)$ & $865(51)$ & $884(50.9)$ & \multirow[t]{2}{*}{0.375} \\
\hline Right & $24(55.8)$ & $830(49)$ & $854(49.1)$ & \\
\hline \multicolumn{5}{|l|}{$\operatorname{ER}(n=1738)$} \\
\hline Positive & $9(20.9)$ & $1019(60.1)$ & $1028(59.1)$ & \multirow[t]{2}{*}{$\leq 0.05$} \\
\hline Negative & $34(79.1)$ & $676(39.9)$ & $710(40.9)$ & \\
\hline \multicolumn{5}{|l|}{$\operatorname{PR}(n=1738)$} \\
\hline Positive & $6(14)$ & $779(46)$ & $785(45.2)$ & \multirow[t]{2}{*}{$\leq 0.05$} \\
\hline Negative & $37(86)$ & $916(54)$ & $953(54.8)$ & \\
\hline \multicolumn{5}{|c|}{ Her2neu $(n=1738)$} \\
\hline Positive & $9(20.9)$ & $742(43.8)$ & $751(43.2)$ & \multirow[t]{2}{*}{$\leq 0.05$} \\
\hline Negative & $34(79.1)$ & $953(56.2)$ & $987(56.8)$ & \\
\hline \multicolumn{5}{|c|}{ Lymphocytic infiltration $(n=660)$} \\
\hline Absent & $10(38.5)$ & $364(57.4)$ & $374(56.7)$ & 0.132 \\
\hline Moderate & $13(50)$ & $210(33.1)$ & $223(33.8)$ & \\
\hline Severe & $3(11.5)$ & $60(9.5)$ & $63(9.5)$ & \\
\hline
\end{tabular}

Table 1 (continued)

\begin{tabular}{|c|c|c|c|c|}
\hline & \multicolumn{3}{|l|}{ n (\%) } & \multirow[t]{2}{*}{ P-value } \\
\hline & Metaplastic & Ductal, NOS & Total & \\
\hline \multicolumn{5}{|c|}{ Insitu component $(n=659)$} \\
\hline Present & $11(42.3)$ & $432(68.2)$ & $443(67.2)$ & \multirow[t]{2}{*}{$\leq 0.05$} \\
\hline Absent & $15(57.7)$ & $201(31.8)$ & $216(32.8)$ & \\
\hline \multicolumn{5}{|c|}{ Lymphovascular invasion $(n=660)$} \\
\hline Present & $8(30.8)$ & $157(24.8)$ & $165(25)$ & \multirow[t]{2}{*}{0.488} \\
\hline Absent & $18(69.2)$ & $477(75.2)$ & $495(75)$ & \\
\hline \multicolumn{5}{|c|}{ Dermal lymphatic invasion $(n=660)$} \\
\hline Present & $0(0)$ & $78(12.3)$ & $78(11.8)$ & \multirow[t]{2}{*}{0.061} \\
\hline Absent & $26(100)$ & $556(87.7)$ & $582(88.2)$ & \\
\hline \multicolumn{5}{|c|}{ Pagetoid spread $(n=660)$} \\
\hline Present & $0(0)$ & $14(2.2)$ & $14(2.1)$ & \multirow[t]{2}{*}{1.000} \\
\hline Absent & $26(100)$ & $620(97.8)$ & $646(97.9)$ & \\
\hline \multicolumn{5}{|c|}{ Molecular subtypes $(n=1738)$} \\
\hline Triple negative & $29(67.4)$ & $298(17.6)$ & $327(18.8)$ & \multirow[t]{4}{*}{$\leq 0.05$} \\
\hline HER 2 & $5(11.6)$ & $363(21.4)$ & $368(21.2)$ & \\
\hline Luminal A & $1(2.3)$ & $287(16.9)$ & $288(16.6)$ & \\
\hline Luminal B & $8(18.6)$ & $747(44.1)$ & $755(43.4)$ & \\
\hline
\end{tabular}

Chi Square applied

a Mean \pm SD

b Independent t-Test

year 2014, revealed that the incidence of tumors demonstrating ductal morphology was as high as $83 \%$ in the population [15]. Furthermore, a meaningful number of tumors exhibited metaplastic as well as medullary characteristics $[14,15]$. On the grounds of our previous findings; in this study we focused on the clinico-pathologic and histopathologic features of the invasive micropapillary breast carcinoma and the invasive metaplastic carcinoma. Alongside studying these clinico-pathologic features of invasive metaplastic and micropapillary breast carcinoma, we also compared the two subtypes with the invasive ductal carcinoma, not otherwise specified of the breast to expand our knowledge and understanding.

According to Weigelt et al. only $25 \%$ of carcinomas diagnosed in laboratory settings are histologically 'special type' and further classified into 17 pathological types, while the rest are invasive ductal carcinoma not otherwise specified [16]. In congruence with the previous studies, we observed that ductal carcinoma, not otherwise specified were the most prevalent type of breast cancer in our population, constituting $84 \%$ of all breast cancers diagnosed in the laboratory, while only a meagre number of cases of metaplastic (2.2\%) and micropapillary $(0.76 \%)$ carcinomas were notable. The incidence of metaplastic carcinoma was found to be less than $1 \%$ by previous studies [17-20], however, in the present study, 
Table 2 Association of clinico-pathologic parameters of micropapillary breast cancer subtype with ductal carcinoma, NOS

\begin{tabular}{|c|c|c|c|c|}
\hline & \multicolumn{3}{|l|}{ n (\%) } & \multirow[t]{2}{*}{ P-value } \\
\hline & Micropapillary & Ductal, NOS & Total & \\
\hline Age (years) ${ }^{\mathrm{ab}}$ & $48.20 \pm 14.02$ & $50.54 \pm 12.48$ & - & 0.47 \\
\hline \multicolumn{5}{|c|}{ Age group $(n=1710)$} \\
\hline$\leq 30$ & $2(13.3)$ & $89(5.3)$ & $91(5.3)$ & \multirow[t]{4}{*}{0.323} \\
\hline $31-50$ & $7(46.7)$ & $822(48.5)$ & $829(48.5)$ & \\
\hline $51-70$ & $5(33.3)$ & $692(40.8)$ & $697(40.8)$ & \\
\hline$>70$ & $1(6.7)$ & $92(5.4)$ & $93(5.4)$ & \\
\hline \multicolumn{5}{|c|}{ Tumor grade $(n=1710)$} \\
\hline Grade 1 & $0(0)$ & $160(9.4)$ & $160(9.4)$ & \multirow[t]{3}{*}{0.386} \\
\hline Grade 2 & $11(73.3)$ & $945(55.8)$ & $956(55.9)$ & \\
\hline Grade 3 & $4(26.7)$ & $590(34.8)$ & $594(34.7)$ & \\
\hline Ki67 value ${ }^{\mathrm{ab}}$ & $35.80 \pm 22.94$ & $35.92 \pm 23.33$ & - & 0.984 \\
\hline \multicolumn{5}{|c|}{ Ki67 index category $(n=1710)$} \\
\hline$<15$ & $2(13.3)$ & $373(22)$ & $375(21.9)$ & \multirow[t]{4}{*}{0.582} \\
\hline $15-24$ & $4(26.7)$ & $311(18.3)$ & $315(18.4)$ & \\
\hline $25-44$ & $5(33.3)$ & $406(24)$ & $411(24)$ & \\
\hline$>44$ & $4(26.7)$ & $605(35.7)$ & $609(35.6)$ & \\
\hline Size of tumor ab & $33.11 \pm 14.77$ & $36.11 \pm 14.84$ & - & 0.547 \\
\hline \multicolumn{5}{|c|}{ Tumor stage $(n=643)$} \\
\hline $\mathrm{T} 1$ & $1(11.1)$ & $83(13.1)$ & $84(13.1)$ & \multirow[t]{3}{*}{1.000} \\
\hline $\mathrm{T} 2$ & $7(77.8)$ & 454 (71.6) & $461(71.7)$ & \\
\hline T3 & $1(11.1)$ & $97(15.3)$ & $98(15.2)$ & \\
\hline \multicolumn{5}{|c|}{ Nodal status $(n=643)$} \\
\hline Positive & $6(66.7)$ & $318(50.2)$ & $324(50.4)$ & \multirow[t]{2}{*}{0.505} \\
\hline Negative & $3(33.3)$ & $316(49.8)$ & $319(49.6)$ & \\
\hline \multicolumn{5}{|l|}{$N$ stage $(n=643)$} \\
\hline No & $4(44.4)$ & $320(50.5)$ & $324(50.4)$ & \multirow[t]{4}{*}{0.417} \\
\hline N1 & $2(22.2)$ & $130(20.5)$ & $132(20.5)$ & \\
\hline N2 & $0(0)$ & 85 (13.4) & $85(13.2)$ & \\
\hline N3 & $3(33.3)$ & $99(15.6)$ & $102(15.9)$ & \\
\hline \multicolumn{5}{|c|}{ Laterality $(n=1710)$} \\
\hline Left & $9(60)$ & $865(51)$ & $874(51.1)$ & \multirow[t]{2}{*}{0.489} \\
\hline Right & $6(40)$ & $830(49)$ & $836(48.9)$ & \\
\hline \multicolumn{5}{|l|}{$E R(n=1710)$} \\
\hline Positive & $13(86.7)$ & $1019(60.1)$ & $1032(60.4)$ & \multirow[t]{2}{*}{$\leq 0.05$} \\
\hline Negative & $2(13.3)$ & $676(39.9)$ & 678 (39.6) & \\
\hline \multicolumn{5}{|l|}{$P R(n=1710)$} \\
\hline Positive & $11(73.3)$ & $779(46)$ & $790(46.2)$ & \multirow[t]{2}{*}{$\leq 0.05$} \\
\hline Negative & $4(26.7)$ & $916(54)$ & $920(53.8)$ & \\
\hline \multicolumn{5}{|c|}{ Her2neu $(n=1710)$} \\
\hline Positive & $9(60)$ & $742(43.8)$ & $751(43.9)$ & \multirow[t]{2}{*}{0.207} \\
\hline Negative & $6(40)$ & $953(56.2)$ & $959(56.1)$ & \\
\hline \multicolumn{5}{|c|}{ Lymphocytic infiltration $(n=643)$} \\
\hline Absent & $3(33.3)$ & $364(57.4)$ & $367(57.1)$ & 0.241 \\
\hline Moderate & $5(55.6)$ & $210(33.1)$ & $215(33.4)$ & \\
\hline Severe & $1(9.5)$ & $60(9.5)$ & $61(9.5)$ & \\
\hline
\end{tabular}

Table 2 (continued)

\begin{tabular}{|c|c|c|c|c|}
\hline & \multicolumn{3}{|l|}{ n (\%) } & \multirow[t]{2}{*}{ P-value } \\
\hline & Micropapillary & Ductal, NOS & Total & \\
\hline \multicolumn{5}{|c|}{ Insitu component $(n=642)$} \\
\hline Present & $2(22.2)$ & $432(68.2)$ & $434(67.6)$ & \multirow[t]{2}{*}{$\leq 0.05$} \\
\hline Absent & $7(77.8)$ & $201(31.8)$ & $208(32.4)$ & \\
\hline \multicolumn{5}{|c|}{ Lymphovascular invasion $(n=643)$} \\
\hline Present & $7(77.8)$ & $157(24.8)$ & $164(25.5)$ & \multirow{2}{*}{$\leq 0.05$} \\
\hline Absent & $2(22.2)$ & $477(75.2)$ & $479(74.5)$ & \\
\hline \multicolumn{5}{|c|}{ Dermal lymphatic invasion $(n=643)$} \\
\hline Present & $2(2.5)$ & $78(12.3)$ & $80(12.4)$ & \multirow[t]{2}{*}{0.311} \\
\hline Absent & $7(77.8)$ & $556(87.7)$ & $563(87.6)$ & \\
\hline \multicolumn{5}{|c|}{ Pagetoid spread $(n=643)$} \\
\hline Present & $0(0)$ & $14(2.2)$ & $14(2.2)$ & \multirow[t]{2}{*}{1.000} \\
\hline Absent & $9(100)$ & $620(97.8)$ & $629(97.8)$ & \\
\hline \multicolumn{5}{|c|}{ Molecular subtypes $(n=1710)$} \\
\hline Triple negative & $1(6.7)$ & $298(17.6)$ & $299(17.5)$ & \multirow[t]{4}{*}{$\leq 0.05$} \\
\hline HER 2 & $1(6.7)$ & $363(21.4)$ & $364(21.3)$ & \\
\hline Luminal A & $0(0)$ & $287(16.9)$ & $287(16.8))$ & \\
\hline Luminal B & $13(86.7)$ & $747(44.1)$ & $760(44.4)$ & \\
\hline
\end{tabular}

Chi Square applied

a Mean \pm SD

${ }^{b}$ Independent t-Test

we observed that the incidence of $\mathrm{MBC}$ has increased significantly (2.2\% in the present study).

In addition, a marked variation in tumor grade and frequency of ER and PR genes was noticed between the metaplastic and ductal carcinoma not otherwise specified, where metaplastic carcinomas were characterized by high tumor grade as compared to IDC NOS. Since tumor grade is one of the predominant histopathologic feature that predicts the outcome of disease [21-23]. It can be said that metaplastic carcinoma is more aggressive in behavior than IDC NOS. Moreover, the ER and PR positivity was significantly low in our study. A previous study also demonstrated that the percentage of ER, PR and HER-2 positivity was less than $10 \%$ in metaplastic carcinoma [18]. Our analysis also showed congruence with these findings as HER-2 positivity was found to be $21 \%$ in metaplastic carcinomas and $44 \%$ in invasive ductal carcinoma, not otherwise specified.

Furthermore, a significant number of metaplastic carcinoma were found to be triple negative (84\%), unlike DC, NOS which were predominantly luminal B type. The findings of our study are consistent with other studies which demonstrated that triple negative characteristic was the predominant molecular subtype in metaplastic carcinoma [18, 25]. Due to triple negative characteristic of metaplastic carcinomas, they are regarded as more aggressive type of cancers which are often less-responsive to endocrine therapy [24]. 
On the other hand, the incidence of invasive micropapillary carcinoma was reported to be less than $2 \%$ (ranging from 0.7 to $3 \%$ ) of all invasive breast carcinomas [24, $25]$. In our study, we found that less than $1 \%$ of the cases of breast cancers accounted for invasive micropapillary carcinoma. The clinico-pathologic findings of micropapillary carcinoma in our study revealed a high ER and PR positivity ratio as compared with invasive ductal carcinoma, not otherwise specified. ER positivity was visible in $87 \%$ of the cases of IMPC, while only $60 \%$ of IDC, NOS showed ER positivity. In another study, ER positivity ranged from 19.4 to $90.6 \%$ in invasive micropapillary carcinomas [26]. One of the study also indicated that high PR positivity in invasive micropapillary carcinomas is advantageous in terms of survival and attributable to increased life expectancy in these patients. Therefore, these characteristics suggest good prognosis in patients with MIBC as compared to IDC, NOS since high positivity of ER and PR correlates with good prognosis and tumor outcomes [27, 28] Notwithstanding with these correlations, the IMPC is characterized by poor prognosis and aggressive behavior due to high propensity for nodal metastasis and lymphovascular invasion [27, 28], despite of high PR and ER positivity. The findings of our study reaffirm high incidence of lymphovascular invasion, as noted in $78 \%$ of micropapillary carcinomas compared to only $25 \%$ ductal carcinoma NOS.

In conclusion, invasive micropapillary carcinoma and invasive metaplastic carcinoma are rare breast cancer subtypes accounting for less than 2 and $1 \%$ of the breast cancer burden in our population. Both of the types correlate with adverse prognosis and poor outcomes. Owing to high tumor grade and loss of hormonal receptor expression in metaplastic carcinomas, they are believed to be less responsive to conventional therapies. Similarly, frequent lymphovascular invasion in micropapillary carcinoma correlates with aggressive nature.

We recommend larger-scale, population level studies to find the prevalence of the two rare subtypes of the breast cancer in our population since the results of our study cannot be extrapolated to the whole population as it dealt with a single-facility data. A multi-center study can determine the true prevalence of these rare subtypes of breast cancer in our population and then by knowing the adverse prognostic features of these tumors, therapeutic protocols can be developed for locoregional population.

\section{Limitations}

Lack of clinical follow up to determine recurrence and disease free survival was the major limitation of our study. Moreover, molecular studies like oncotype Dx was not performed on these tumors to determine their molecular adverse prognostic features.

\section{Abbreviations}

DC, NOS: invasive ductal carcinoma, not otherwise specified; MBC: metaplastic breast carcinomas; IMBC: invasive micropapillary breast carcinomas.

\section{Authors' contributions}

AAH, SA and SMK: main author of manuscript, have made substantial contributions to conception and design of study. RM, MIZ, NI MN, MS, NF, MME AND AK have been involved in requisition, analysis of the data and gave final approval and revision of the manuscript. All authors read and approved the final manuscript.

\section{Author details \\ ${ }^{1}$ Liaquat National Hospital and Medical College, Karachi, Pakistan. ${ }^{2}$ Shaheed Zulfiqar Ali Bhutto Institute of Science and Technology, Karachi, Pakistan. \\ ${ }^{3}$ Department of Statistics, Liaquat National Hospital and Medical College, Karachi, Pakistan. ${ }^{4}$ Aga Khan University, Karachi, Pakistan. ${ }^{5}$ Department of Pathology, National Hospital and Medical College, Karachi, Pakistan. \\ ${ }^{6}$ Department of Surgery, Brown University, Providence, RI, USA. ${ }^{7}$ Department of Medicine, Kandahar University, Kandahar, Afghanistan.}

\section{Acknowledgements}

We gratefully acknowledge all staff members of Pathology, Liaquat National Hospital, Karachi, Pakistan for their help and cooperation.

\section{Competing interests}

The authors declare that they have no competing interests.

\section{Availability of data and materials}

Please contact author for data requests.

\section{Consent to publish}

Not applicable.

\section{Ethics approval and consent to participate}

Ethics committee of Liaquat National Hospital, Karachi, Pakistan approved the study. Written informed consent was obtained from the patients for the participation.

\section{Funding}

No Funding was provided.

\section{Publisher's Note}

Springer Nature remains neutral with regard to jurisdictional claims in published maps and institutional affiliations.

Received: 9 May 2018 Accepted: 20 July 2018

Published online: 31 July 2018

\section{References}

1. Carstens PHB, Greenberg RA, Francis D, Lyon H. Tubular carcinoma of the breast. A long term follow-up. Histopathology. 1985;9:271-80.

2. Clayton F. Pure mucinous carcinomas of breast: morphologic features and prognostic correlates. Hum Pathol. 1986;17:34-8.

3. Fisher ER, Palekar AS, Redmond C, Barton B, Fisher B. Pathologic findings from the National Surgical Adjuvant Breast Project (protocol no. 4) VI. Invasive papillary cancer. Am J Clin Pathol. 1980;73:313-22.

4. Pettinato G, Manivel CJ, Panico L, Sparano L, Petrella G. Invasive micropapillary carcinoma of the breast: clinicopathologic study of 62 cases of a poorly recognized variant with highly aggressive behavior. Am J Clin Pathol. 2004:121(6):857-66.

5. Siriaunkgul S, Tavassoli FA. Invasive micropapillary carcinoma of the breast. Mod Pathol. 1993;6:660-2. 
6. Luna-More S, Gonzalez B, Acedo C, Rodrigo I, Luna C. Invasive micropapillary carcinoma of the breast. A new special type of invasive mammary carcinoma. Pathol Res Pract. 1994:190:668-74.

7. Reis-Filho JS, Milanezi F, Steele D, et al. Metaplastic breast carcinomas are basal-like tumours. Histopathology. 2006;49:10-21.

8. Hashmi AA, Edhi MM, Naqvi H, Khurshid A, Faridi N. Molecular subtypes of breast cancer in South Asian population by immunohistochemical profile and Her2neu gene amplification by FISH technique: association with other clinicopathologic parameters. Breast J. 2014;20(6):578-85.

9. Lacroix-Triki M, Geyer FC, Lambros MB, et al. $\beta$-catenin/Wnt signalling pathway in fibromatosis, metaplastic carcinomas and phyllodes tumours of the breast. Mod Pathol. 2010;23:1438-48.

10. Mani SA, Guo W, Liao MJ, et al. The epithelial-mesenchymal transition generates cells with properties of stem cells. Cell. 2008;133:704-15.

11. Wolff AC, Hammond ME, Schwartz JN, et al. American Society of Clinical Oncology/College of American Pathologists guideline recommendations for human epidermal growth factor receptor 2 testing in breast cancer. Arch Pathol Lab Med. 2007;131(1):18-43.

12. Wolff AC, Hammond ME, Hicks DG, et al. Recommendations for human epidermal growth factor receptor 2 testing in breast cancer: American Society of Clinical Oncology/College of American Pathologists (ASCO/CAP) Clinical Practice Guideline Update. Arch Pathol Lab Med. 2013;138:241-56

13. Ellis IO, Galea M, Broughton N, Locker A, Blamey RW, Elston CW. Pathological prognostic factors in breast cancer. II. Histological type. Relationship with survival in a large study with long-term follow-up. Histopathology. 1992;20(6):479-89.

14. Hashmi AA, Edhi MM, Naqvi H, Faridi N, Khurshid A, Khan M. Clinicopathologic features of triple negative breast cancers: an experience from Pakistan. Diagn Pathol. 2014;9:43. https://doi.org/10.1186/1746-1596-9-43.

15. Hashmi AA, Naz S, Hashmi SK, Hussain ZF, Irfan M, Bakar SMA, Faridi N, Khan A, Edhi MM. Cytokeratin 5/6 and cytokeratin 8/18 expression in triple negative breast cancers: clinicopathologic significance in South-Asian population. BMC Res Notes. 2018;11(1):372.

16. Weigelt $B$, Horlings HM, Kreike B, Hayes MM, Hauptmann M, Wessels LF, De Jong D, Van de Vijver MJ, Van't Veer LJ, Peterse JL. Refinement of breast cancer classification by molecular characterization of histological special types. J Pathol. 2008;216(2):141-50.

17. Tavassoli FA. Classification of metaplastic carcinomas of the breast. Pathol Annu. 1992;27:89-119.

18. Park HS, Park S, Kim JH, Lee JH, Choi SY, Park BW, Lee KS. Clinicopathologic features and outcomes of metaplastic breast carcinoma: comparison with invasive ductal carcinoma of the breast. Yonsei Med J. 2010;51(6):864-9.

19. Park JH, Han W, Kim SW, Lee JE, Shin HJ, Kim SW, Choe KJ, Oh SK, Youn YK, Noh DY. The clinicopathologic characteristics of 38 metaplastic carcinomas of the breast. J Breast Cancer. 2005;8(2):59-63.

20. Hashmi AA, Aijaz S, Khan SM, Mahboob R, Irfan M, Zafar NI, Nisar M, Siddiqui M, Edhi MM, Faridi N, Khan A. Prognostic parameters of luminal A and luminal B intrinsic breast cancer subtypes of Pakistani patients. World J Surg Oncol. 2018;16(1):1.

21. Buerger H, Mommers EC, Littmann R, Simon R, Diallo R, Poremba C, Dockhorn-Dworniczak B, van Diest PJ, Boecker W. Ductal invasive G2 and $\mathrm{G} 3$ carcinomas of the breast are the end stages of at least two different lines of genetic evolution. J Pathol. 2001;194(2):165-70.

22. Reis-Filho JS, Lakhani SR. The diagnosis and management of pre-invasive breast disease Genetic alterations in pre-invasive lesions. Breast Cancer Res. 2003;5(6):313.

23. Simpson PT, Reis-Filho JS, Gale T, Lakhani SR. Molecular evolution of breast cancer. J Pathol. 2005;205(2):248-54.

24. Tavassoli FA, Devilee P, editors. Pathology and genetics of tumours of the breast and female genital organs. Lyon: IARC; 2003.

25. Cui ZQ, Feng JH, Zhao YJ. Clinicopathological features of invasive micropapillary carcinoma of the breast. Oncol Lett. 2015;9(3):1163-6.

26. Chen AC, Paulino AC, Schwartz MR, Rodriguez AA, Bass BL, Chang JC, Teh BS. Population-based comparison of prognostic factors in invasive micropapillary and invasive ductal carcinoma of the breast. Br J Cancer. 2014;111(3):619.

27. Kim DS, Cho N, Ko ES, Kim DY, Yang SK, Kim SJ, Moon WK. Imaging and the clinical-pathologic features of invasive micropapillary carcinoma of the breast. J Korean Radiol Soc. 2007;56(5):497-503.

28. Walsh MM, Bleiweiss IJ. Invasive micropapillary carcinoma of the breast: eighty cases of an underrecognized entity. Hum Pathol. 2001;32(6):583-9.
Ready to submit your research? Choose BMC and benefit from:

- fast, convenient online submission

- thorough peer review by experienced researchers in your field

- rapid publication on acceptance

- support for research data, including large and complex data types

- gold Open Access which fosters wider collaboration and increased citations

- maximum visibility for your research: over $100 \mathrm{M}$ website views per year

At BMC, research is always in progress.

Learn more biomedcentral.com/submissions 